\title{
O Modelo Z-D e a Função Emprego - Descrições Gráficas à Luz da Teoria Geral de Keynes ${ }^{\star}$
}

\author{
- Claudia Heller*
}

\begin{abstract}
Resumo
Este artigo compara três versões do modelo Z-D que descrevem graficamente a função emprego de Keynes. Ao mesmo tempo, o artigo corrige a redação dada por Keynes, na Teoria Geral, à descrição desta função. $\mathrm{O}$ artigo conclui que as versões em pauta têm o mérito de demonstrar que é possível descrever a função emprego através de um diagrama inspirado no conceito de demanda efetiva e considerando suposições menos restritas que as utilizadas por Keynes.
\end{abstract}

\section{Palavras-Chave}

Keynes, função emprego, modelo Z-D, Princípio da Demanda Efetiva

\begin{abstract}
The paper compares three versions of the Z-D model that diagrammatically describe Keynes's employment function. The paper also corrects Keynes's verbal description of the employment function in the General Theory. The papers comes to the conclusion that the three compared versions prove that it is possible to describe the employment function through a diagram based on the concept of effective demand and taking into account less restrictive assumptions than those assumed by Keynes.
\end{abstract}

\section{Keywords}

Keynes, employment function, Z-D model, Principle of Effective Demand

\section{JEL Classification}

$B 2, B 22$

- Agradeço à FAPESP pela oportunidade de debater uma versão preliminar deste texto no $V$ Encontro Ibérico de História do Pensamento Econômico, em Madrid. Agradeço também os valiosos comentários de Rogério Arthmar, Michael Brady, Renata Cipolli D’Arbo, Marina Vessio Dessotti, Rodolphe dos Santos Ferreira e Fausto Saretta, bem como os dos pareceristas anônimos. Como de praxe, estão todos isentos de eventuais erros e omissões.

* Departamento de Economia, Universidade Estadual Paulista “Júlio de Mesquita Filho" (Unesp). E-mail: hellerc@terra.com.br.

Endereço para contato: Rod. Araraquara-Jaú, km 1 - Araraquara - SP. CEP: 14800-901.

(Recebido em janeiro de 2009. Aceito para publicação em abril de 2010). 


\section{Introdução}

A Teoria Geral do Emprego, dos Juros e da Moeda de John Maynard Keynes deu origem a três interpretações gráficas na forma de cruz: o modelo IS-LM, o modelo da reta de $45^{\circ}$ e o modelo $Z$ - $D$. O surgimento e a evolução destas interpretações são temas bastante controversos na literatura, e difíceis de sintetizar. De modo muito genérico, pode-se dizer que o primeiro modelo derivou do célebre artigo de Hicks (1937), que o segundo tornou-se conhecido a partir do livro de Alvin Hansen (1953) e que o terceiro popularizou-se com os livros de Dudley Dillard (1948) e de Victoria Chick (1983). Todos eles são tentativas de formalizações gráficas (em alguns casos também algébricas) da teoria proposta por Keynes, mas os dois últimos são mais específicos, pois referem-se diretamente ao Princípio da Demanda Efetiva (PDE). ${ }^{1}$

O presente artigo compara três versões gráficas do modelo $Z$ - $D$ - a de Victoria Chick; a de Rodolphe dos Santos Ferreira e Philippe Michel, e a de Michael Emmett Brady -, tomando como ponto de partida a função demanda agregada $D=f(N)$, a função oferta agregada $Z=\phi(N)$ e o conceito de demanda efetiva de acordo com a formalização algébrica proposta na Teoria Geral. A seleção destes autores deve-se ao fato de proporem um diagrama específico para representar a função emprego de Keynes com base no modelo $Z-D .^{2}$ A comparação proposta enfatiza a formulação

1 Esta afirmação não contradiz as interpretações que consideram que o modelo da reta de $45^{\circ}$ é uma versão simplificada do modelo IS-LM, em que a simplificação reside na ausência do mercado monetário e da taxa de juros. A rigor, de acordo com este critério, o modelo da reta de $45^{\circ}$ é ainda mais semelhante ao modelo $Z-D$, que tampouco trata de moeda ou juros.

2 Desde a publicação da Teoria Geral, foram inúmeras as tentativas de representação das ideias centrais do livro de Keynes por meio de diagramas e/ou de formalização algébrica. Neste artigo, analisamos as que privilegiaram a representação gráfica da função emprego, mas é possível listar um grande conjunto de autores que trataram do tema com ênfase na álgebra. A controvérsia original deu-se no Economic Journal com a publicação do artigo de Patinkin (1949) e, inicialmente, envolveu De Jong (1954a, 1954b, 1955, 1956), Hawtrey (1954, 1956), Robertson e Johnson (1955), Robertson (1956), Weintraub (1957), Wells (1960, 1961), Marty (1961), Veendorp e Werkema (1961), Kooros (1961), Neissen (1961) e Davidson (1962). Vinte anos depois, o tema foi retomado no mesmo periódico por Casarosa $(1981,1984)$ e Torr (1984). Somando-se às contribuições na forma de livros ou capítulos de livros, como Weintraub (1951, 1961), Davidson e Smolensky (1964), Tarshis (1947, 1979), Casarosa (1982), Patinkin (1984), Amadeo (1989), Pasinetti (1997) e Brady (2004) - entre outros - deve-se mencionar também os vários periódicos que publicaram debates ou artigos isolados em torno da formalização da oferta agregada na Teoria Geral: South African Journal of Economics (SOPER, 1956; TORR 1981), Metroeconomica (MARTY, 1959), Canadian Journal of Economics and Political Sciences (WELLS, 1962), International Economic Review (KLEVORICK, 1966), Quarterly Review of Economics and Business (WELLS, 1973), Rivista di Politica Economica (CASAROSA, 1978), Economic Enquiry (PATINKIN, 1979; MARTY 1981), Revue Économique (KOENIG, 1980, 1986), Journal of Post Keynesian Economics (PARRINELLO, 1980; AMBROSI, 1981; VICKERS, 1987; NEVILE, 1992; CHICK, 1992; KING, 1994), Review of Political Economy (TORR, 1992), Australian Economic Papers (ASIMAKOPULOS, 1982), History of Economics Review (BRADY, 1996), Indian Journal of Applied Economics (BRADY, 1999a, 1999b) e European Journal for the History of Economic Thought (HARTWIG, 2007). As contribuições no Journal of Post Keynesian Economics são o tema central de Brady (2004b). O periódico History of Political Economy também publicou um debate 
da função emprego $N=\mathrm{F}(Z=D)$, também de acordo com Keynes, e para isso necessita da discussão dos conceitos de função de produção $\mathrm{O}=\psi(N)$ e de curva de oferta agregada $p=\mathrm{Z} / \mathrm{O}=\phi(N) / \psi(N)$. O detalhamento destas formulações (e uma correção necessária à Teoria Geral) é feito na primeira seção deste trabalho, para a qual recorremos às sugestões de Victoria Chick (no que diz respeito à generalização das hipóteses mais restritivas utilizadas por Keynes) e de Michael Emmett Brady (no que se refere ao desenvolvimento da argumentação algébrica que Keynes deixa apenas indicada).

Com os resultados da primeira seção, a seguinte analisa a interpretação de Victoria Chick, tomando como referência seu livro de 1983, que é a versão mais popular do modelo - e mais completa que a de Dillard (1948), uma vez que inclui considerações sobre o mercado de trabalho. Os resultados da primeira seção também são utilizados na terceira seção, que avalia as contribuições menos conhecidas de Ferreira e Michel $(1988,1991)$ caracterizadas por considerarem diferentes níveis de preços esperados e seus efeitos tanto sobre a função oferta agregada quanto sobre a função demanda agregada. ${ }^{3}$ A quarta seção também usa os resultados da primeira e trata da contribuição de Michael Emmett Brady (1996), que apresenta uma interpretação do papel do mercado de trabalho que corrige problemas da versão de Chick. ${ }^{4}$

Na última seção - que conclui o texto -, comparamos as três interpretações e sintetizamos as suposições que podem ser generalizadas numa descrição gráfica da função emprego de Keynes (1936), o que permite potencialmente avançar em direção ao desenvolvimento da teoria keynesiana com um caráter mais formal.

\section{A Formulação Algébrica Proposta por Keynes na Teoria Geral}

Uma exposição completa da Teoria Geral, no contexto deste artigo, seria excessiva, bem como a discussão do papel do princípio da demanda efetiva para a teoria keynesiana. O mesmo se aplica à discussão da noção de equilíbrio empregada por Keynes à problemática questão da agregação, ou ainda ao conceito de concorrência.

sobre a cruz keynesiana na versão Z-D, em 1974, entre Wells, Leijonhufvud e Weintraub. A estes seguiram-se Henneberry e Witte (1976) e Patinkin (1976) e novos aportes de Roberts (1978), Patinkin (1977, 1978, 1989), Dickson (1983), Fusfeld (1985, 1989), Davidson (1989a, 1989b) e Brady (1990). Estes estão analisados em Brady (2004c). O tema permanece em discussão até hoje, como se pode verificar pela controvérsia recente entre Hayes $(2007,2008)$ e Hartwig e Brady (2008) no Cambridge Journal of Economics. Finalmente, merece menção o artigo de Arthmar e Brady (2009) publicado na History of Economic Ideas.

3 Como se verá adiante, nos textos destes autores, a curva de oferta agregada de certa forma se confunde com a função oferta agregada e consequentemente com a função emprego.

4 Ver-se-á que, embora enfatize a distinção entre a curva de oferta agregada e a função oferta agregada, Brady confunde a segunda com a função emprego. 
São temas cuja relevância (e grau de controvérsia) não permite que sejam abordados no âmbito da discussão que propomos neste artigo.

O que se pretende nesta seção é apenas explicitar as definições de demanda agregada, oferta agregada, demanda efetiva, função de produção, função emprego e curva de oferta agregada, bem como as respectivas formalizações algébricas propostas por Keynes, que serviram de base para as representações gráficas (e algébricas) elaboradas por alguns intérpretes. O objetivo é explicitar a base comum destas diferentes interpretações - que está na Teoria Geral - para dar conta de suas semelhanças e diferenças. Na medida do possível, a apresentação dos conceitos utiliza uma notação adaptada de forma a viabilizar as comparações. Assim, no que segue, usaremos $N$ para nível de emprego, $\mathrm{O}$ para produto, $D$ para demanda (com $D^{\mathrm{EF}}$ para demanda efetiva), C para consumo, $I$ para investimento, $p$ para preços, $P$ (e eventualmente $\pi$ ) para lucros, $W$ para salários nominais, $U$ para custo de uso e $Y$ para renda. $O$ sobrescrito "e" indica valores esperados (e.g.: $P^{e}$ é lucro esperado), o subscrito " $W$ " indica que os valores são medidos em unidades de salário $\left(Y_{\mathrm{W}}=Y / W\right)$ e o subscrito "r" indica algum grau de desagregação. Em particular:

- $\quad Z=\phi(N)$ é a função oferta agregada (KEYNES, 1936, p. 25);

- $\quad D=f(N)$ é a função demanda agregada (KEYNES, 1936, p. 25-29) ${ }^{5}$;

- $O=\psi(N)$ é a função de produção (KEYNES, 1936, p. 44) 6

- $\quad N=F\left(D^{\mathbb{E}}\right)$ é a função emprego, que também pode ser escrita como $N=F(Z=D)\left(\right.$ KEYNES, 1936, p. 280); ${ }^{7}$

$p=\frac{Z+U(N)}{O}=\frac{\phi(N)+U(N)}{\psi(N)}$ é a curva de oferta agregada (Keynes, 1936, p. 44).

Esta seção está organizada em duas partes. Na primeira, tratamos das funções oferta agregada e demanda agregada e do conceito de demanda efetiva, que servem de base para a discussão mais relevante deste texto, que é a distinção entre os conceitos de função e curva de oferta agregada, e entre estes dois e o de função emprego, tratados na segunda parte.

5 Com $D=D_{1}+D_{2}$, onde $D_{1}=\chi(N)$ é a função consumo C (em que $\chi$ é a propensão a consumir) e $D_{2}$ é a função investimento $I$.

6 Adotaremos a notação que Keynes utiliza no capítulo 4 em vez da notação do seu capítulo 20, onde a função de produção é descrita por $O=\phi(N)$.

7 Esta notação específica será justificada mais adiante. 


\subsection{Função Oferta Agregada, Função Demanda Agregada e Ponto de Demanda Efetiva}

Keynes define $Z$ como o preço de oferta agregada do produto que resulta do emprego de $N$ homens. A relação entre o preço de oferta $Z$ e o nível de emprego $N$ é descrita por $Z=\phi(N)$ e é chamada função oferta agregada. Trata-se do valor que torna compensatório contratar um dado nível de emprego. Esta definição decorre da suposição de Keynes de que, ao decidirem o nível de emprego a ser contratado, os empresários visam maximizar lucro, considerando o "custo de fator" e o "custo de uso." ${ }^{8}$ Assim, o lucro a ser maximizado pelo empresário é a diferença entre o valor do produto resultante do processo de produção e a soma destes dois custos. Este resultado (um rendimento esperado) é o que induz à contratação de um dado nível de emprego. Para Keynes, a função oferta agregada relaciona-se à função emprego (apresentada por ele no capítulo 20 da Teoria Geral), ambas distintas do que ele chama de curva de oferta agregada. Esta, por sua vez, e ainda de acordo com Keynes, depende da função oferta agregada e da função de produção - como se verá a seguir.

A função demanda agregada $D$ representa o que um empresário espera receber em decorrência das vendas da produção gerada pelo volume de emprego contratado. A relação entre $D$ e $N$ é descrita por $D=f(N)$ (KEYNES, 1936, p. 25). Esta também é uma variável expectacional.

Como se sabe, Keynes considera que a demanda agregada pode ser superior à oferta agregada, isto é, que, para um dado nível de emprego, o rendimento esperado (decorrente das vendas) pode ser maior que o preço de oferta - que compensa a contratação da mão de obra. Neste caso, os empresários se sentirão incentivados a aumentar o nível de emprego, ainda que isto provoque elevação de custos (em consequência, por exemplo, da concorrência interempresarial por fatores de produção que se tornam escassos), até o ponto em que a oferta agregada se iguale à demanda agregada. Para Keynes, este é o ponto que determina o volume de emprego, pois, nele, os empresários maximizam seus lucros esperados (idem, ibidem, p. 24-25). Este ponto é o de demanda efetiva, que, nas representações gráficas, equivale ao intercepto (e eventualmente à tangência) entre a função demanda agregada e a função oferta agregada (idem, ibidem, p. 25). ${ }^{9}$ No restante deste texto, usaremos

8 O primeiro refere-se ao montante a ser pago ao fator de produção, principalmente mão de obra e excluindo-se o que cada empresário paga a outros empresários como, por exemplo, os insumos; o segundo diz respeito ao montante pago por cada empresário aos demais empresários - por exemplo, pelos insumos - e inclui as despesas líquidas decorrentes da utilização do equipamento de capital, tais como a depreciação pelo uso, descontados os gastos com a manutenção do equipamento ocioso.

9 Conforme se verá mais à frente, na suposição de uma função demanda agregada não linear combinada com uma função oferta agregada linear, o "intercepto" se transforma em "ponto de tangência" (Cf. as representações gráficas dos modelos Z-D de Ferreira e Michel e de Brady, mas não de Chick). 
a notação $D^{\mathrm{EF}}$ para demanda efetiva, de modo a distingui-la da função demanda agregada $D$ e descreveremos a função emprego (que relaciona o nível de emprego à demanda efetiva) por $N=\mathrm{F}\left(D^{\mathrm{EF}}\right)$, que equivale a $N=\mathrm{F}(Z=D)$, onde $Z=D$ designa o ponto de demanda efetiva.

A esta altura, é preciso fazer menção à primeira formalização apresentada por Keynes - a que se encontra nas oito proposições constantes do capítulo 3 da Teoria Geral. Nesta primeira formalização, Keynes supõe que tanto os salários nominais quanto os demais custos de fatores são constantes por unidade de emprego utilizada. Supõe também que, quando o nível de emprego aumenta, tanto a renda real quanto o consumo aumentam, mas o consumo aumenta menos do que a renda. Como se sabe, a relação entre a variação da renda e a variação do consumo é chamada de propensão a consumir, e Keynes supõe que o consumo é uma função estável da renda, que a propensão marginal a consumir $\mathrm{dC} / \mathrm{d} Y$ é positiva e menor do que a unidade, e que tanto a propensão média a consumir $\mathrm{C} / Y$ quanto a propensão marginal a consumir $\mathrm{dC} / \mathrm{d} Y$ caem quando a renda aumenta. ${ }^{10}$

A notação utilizada por Keynes ao formalizar os conceitos de demanda agregada e demanda efetiva dá margem à confusão, especialmente a partir da quarta proposição reproduzida a seguir:

since $D_{1}+D_{2}=D=\phi(N)$, where $\phi$ is the aggregate supply function, and since, as we have seen in (2) above, $D_{1}$ is a function of $N$, which we may write $\chi(N)$, depending on the propensity to consume, it follows that $\phi(N)-\chi(N)=D_{2}$. (KEYNES, 1936, $\mathrm{p}$. 29). ${ }^{11}$

O problema desta proposição reside no fato de Keynes reunir várias ideias numa só expressão, nem todas explícitas e sem destacar quais são os valores que são esperados: uma definição $\left(D_{1}+D_{2}=D\right)$, uma condição de equilíbrio $(D=\phi(N))$ e duas definições adicionais $\left(D_{1}=\chi(N)\right.$ e $\left.Z=\phi(N)\right)$. Além disso, o argumento implícito é que, se $D=Z$, então $D_{1}+D_{2}=Z$ e, portanto, $D_{2}=Z-D_{1}$ ou $D_{2}=Z-\chi(N)$, ou ainda $D_{2}=\phi(N)-\chi(N)$. Esta última expressão - explícita na proposição de Keynes - descreve o volume que o investimento deve ter para que o nível de emprego seja o de pleno emprego - dado o montante de consumo. ${ }^{12}$

10 Conforme destacado por Brady (1999b, p. 148), isto significa que a função demanda agregada (entendida como a soma do consumo $\mathrm{C}$ e do investimento $I$ ) não é linear. Todos os autores tratados neste texto concordam e usam esta descrição gráfica da função demanda agregada.

11 No item (2) a que Keynes faz referência, ele afirma que, para uma dada propensão a consumir, o consumo $\left(=D_{1}\right)$ depende do nível de renda e consequentemente do nível de emprego.

12 Daí nasce a representação desta relação por meio da reta de $45^{\circ}$ - como faz Hansen (1953), por exemplo, expressando a interpretação do investimento $\left(=D_{2}\right)$ como um "resíduo" da condição de equilíbrio em que a oferta se iguala à demanda. 
Trata-se, segundo Chick (1983, p. 64), de uma armadilha, já que Keynes usa $D$ tanto para a demanda agregada quanto para a demanda efetiva. Pode-se dizer que aí está uma importante fonte explicativa das diferentes interpretações gráficas da Teoria Geral (o modelo da reta de $45^{\circ}$ e o modelo $Z$ - $D$ - e suas variantes), pois uma coisa é considerar que $D=D_{1}+D_{2}$ (isto é, a definição de que a demanda agregada é composta pela demanda por bens de consumo e pela demanda por bens de investimento) e outra coisa é considerar que $D^{\mathrm{EF}}$ é determinada pela igualdade $D=\phi(N)$, sendo $\phi(N)$ a função oferta agregada $Z$.

\subsection{Função de Produção, Função Emprego e Curva de Oferta Agregada}

Conforme mencionado acima, no capítulo 20 da Teoria Geral, Keynes estabelece uma relação entre a função oferta agregada e a função emprego, e as distingue da curva de oferta agregada. Antes disso, no capítulo 4, estabelece que a curva de oferta agregada depende da função oferta agregada e da função de produção. Ou seja, os conceitos de função de produção, função emprego e curva de oferta agregada estão intimamente relacionados entre si e com a função oferta agregada - que terá que ser retomada aqui.

Keynes escreve que a função oferta agregada é linear com uma inclinação que é a recíproca do salário nominal. Esta concepção é um tema controverso desde as primeiras tentativas de descrever a Teoria Geral por meio de diagramas (ou algebricamente) e deu origem às curvas $Z$ lineares - conforme se verá mais à frente. O ponto de partida de Keynes é a função oferta agregada $Z$, medida em unidades de salário, isto é, considerando o salário nominal $W$ como "deflator", de modo que $Z_{\mathrm{W}}=Z / W$ e, portanto, $Z_{\mathrm{W}}=\phi(N)$ ou $Z=W \cdot \phi(N)$. Além disso, ele supõe que: (i) a função oferta agregada para cada firma ou setor não depende do número de trabalhadores empregados nas demais firmas ou setores; (ii) o número de firmas ou setores não se altera; (iii) os salários nominais não variam, e (iv) os demais custos de fator mantêm uma proporção constante em relação à folha de salários. Para completar, considera que a receita marginal se iguala ao custo marginal em cada ponto da curva de oferta agregada e que o produto marginal do trabalho é constante e igual à unidade, de modo que $\phi^{\prime}(N)=1$. É justamente nesta argumentação, que relegou a uma nota de rodapé, onde ele faz referência à função oferta agregada e à curva de oferta agregada como conceitos distintos. Por esta razão, a referida nota merece ser reproduzida na íntegra:

For example, let us take $Z_{\mathrm{W}}=\phi(N)$, or alternatively $Z=W \cdot \phi(N)$ as the aggregate supply function (where $W$ is the wage-unit and $W \cdot Z_{\mathrm{W}}=Z$ ). Then, since the proceeds of the marginal product is 
equal to the marginal factor-cost at every point on the aggregate supply curve, we have

$\Delta N=\Delta A_{\mathrm{W}}-\Delta U_{\mathrm{W}}-\Delta Z_{\mathrm{W}}=\Delta \phi(N)$

that is to say $\phi^{\prime}(N)=1$; provided that factor cost bears a constant ratio to wage-cost, and that the aggregate supply function for each firm (the number of which is assumed to be constant) is independent of the number of men employed in other industries, so that the terms of the above equation, which hold good for each individual entrepreneur, can be summed for the entrepreneurs as a whole. This means that, if wages are constant and other factor costs are a constant proportion of the wages-bill, the aggregate supply function is linear with a slope given by the reciprocal of the money-wage. (KEYNES, 1936, nota 2, p. 55. Todos os grifos são nossos). ${ }^{13}$

A concepção de que a função oferta agregada é linear com uma inclinação dada pela recíproca do salário nominal é fundamental para a discussão que se pretende neste texto. Ela precisa ser explicada (e corrigida), mas isso requer a apresentação prévia das duas outras funções: a função de produção e a função emprego.

A função de produção $\mathrm{O}=\psi(N)$ é mencionada no final do capítulo 4 da Teoria Geral e está diretamente relacionada à curva de oferta agregada.

... the aggregate supply function for a given firm (and similarly for a given industry or for industry as a whole is given by

$Z_{\mathrm{r}}=\phi_{\mathrm{r}}\left(N_{r}\right)$

where $Z_{\mathrm{r}}$ is the return the expectation of which will induce a level of employment $N_{\mathrm{r}}$. If, therefore, the relation between employment and output is such that an employment $N_{\mathrm{r}}$ results in an output $\mathrm{O}_{\mathrm{r}}$, where $\mathrm{O}_{\mathrm{r}}=\psi_{\mathrm{r}}\left(N_{\mathrm{r}}\right)$, it follows that

$$
p_{r}=\frac{Z_{r}+U_{r}\left(N_{r}\right)}{O_{r}}=\frac{\phi_{r}\left(N_{r}\right)+U_{r}\left(N_{r}\right)}{\psi_{r}\left(N_{r}\right)}
$$

13 Na notação de Keynes, $A$ representa o valor do produto vendido a consumidores e/ou a outros empresários (KEYNES, 1936, p. 52), $U$ é o custo de uso referente a $A$ (idem, ibidem, 1936, p. 53) e $Z$ é a já mencionada função oferta agregada. A demonstração do resultado $\phi^{\prime}(N)=1$ bem como a discussão da inclinação da função oferta agregada (igual à recíproca do salário nominal, segundo Keynes) serão feitas adiante. 
is the ordinary supply curve. (KEYNES, 1936, p. 44, grifos nossos). ${ }^{14}$

Ou seja, a curva de oferta agregada depende da função oferta agregada e da função de produção.

A função emprego, por sua vez, está definida no capítulo 20. Sua relevância também justifica a transcrição na íntegra:

In Chapter 3 (p. 25) we have defined the aggregate supply function $Z=\phi(N)$, which relates the employment $N$ with the aggregate supply price of the corresponding output. The employment function only differs from the aggregate supply function in that it is, in effect, its inverse function and is defined in terms of the wage-unit; the object of the employment function being to relate the amount of the effective demand measured in terms of the wage-unit, directed to a given firm or industry or to industry as a whole with the amount of employment, the supply price of the output of which will compare to that amount of effective demand. Thus if an amount of effective demand $D_{\mathrm{Wr}}$ measured in wage-units, directed to a firm or industry calls forth an amount of employment $N_{\mathrm{r}}$ in that firm or industry, the employment function is given by $N_{\mathrm{r}}=\mathrm{F}_{\mathrm{r}}\left(D_{\mathrm{Wr}_{\mathrm{r}}}\right)$. Or, more generally, if we are entitled to assume that $D_{\mathrm{Wr}_{\mathrm{r}}}$ is a unique function of the total effective demand $D_{\mathrm{w}}$, the employment function is given by $N_{\mathrm{r}}=\mathrm{F}_{\mathrm{r}}\left(D_{\mathrm{W}}\right)$. That is to say, $N_{\mathrm{r}}$ men will be employed in industry $r$ when effective demand is $D_{\mathrm{W}}$. (KEYNES, 1936, p. 280, itálicos no original, grifos nossos).

Destaque-se a concepção de que a função emprego é o inverso da função oferta agregada e que ela relaciona a demanda efetiva (não a demanda agregada!) ao montante de emprego - daí a notação $N=\mathrm{F}(Z=D)$ ou $N=\mathrm{F}\left(D^{E F}\right)$ sugerida neste texto. ${ }^{15}$ Isto permite desenvolver sua formulação algébrica - que, como se verá, é essencial

$14 \mathrm{Na}$ transcrição da equação da curva de oferta agregada, consideramos correta a observação de Brady (2004a, p. 359) de que houve um erro tipográfico na Teoria Geral - onde consta " $p$ " no lugar de " $p_{r}$ ". Esta não é, no entanto, a correção relevante.

15 Há duas observações a fazer em defesa da nossa sugestão de notação. A primeira delas - a mais importante - é que Keynes usa os símbolos $D$ ou $D_{\mathrm{W}}$ embora se refira à demanda efetiva e não à demanda agregada. Há vários exemplos que demonstram esta afirmação, todos eles relacionados às várias medidas de elasticidade que propõe no capítulo que trata da função emprego. A segunda observação é que, embora Keynes descreva a função de produção em nível desagregado (com o subscrito "r"), também considera que é possível usá-la na forma agregada: seu argumento é que se $N=\Sigma N_{\mathrm{r}}$ e se $N_{\mathrm{r}}=\mathrm{F}_{\mathrm{r}}\left(D_{\mathrm{W}}\right)$, então $N=\Sigma N_{\mathrm{r}}=\Sigma \Phi_{\mathrm{r}}\left(D_{\mathrm{W}}\right)$ e a função emprego agregada é $N=\mathrm{F}\left(D_{\mathrm{W}}\right)-$ ou, na notação aqui proposta, $N=\mathrm{F}\left(D^{\mathrm{EF}}\right)$. 
para a descrição gráfica dos modelos $Z$ - $D$ que este texto pretende comparar. Permite também retomar (e corrigir) a descrição da inclinação da função oferta agregada feita por Keynes na referida nota de rodapé da página 55 da Teoria Geral transcrita anteriormente.

Para tanto, supõe-se o curto prazo, de modo que a mão de obra é o único fator de produção variável. Além disso, supõe-se que o salário nominal não se altera, que as firmas atuam em concorrência imperfeita (portanto o preço não é igual à receita marginal) e que não há alterações na composição do produto ou da demanda (isto é, da relação entre consumo e investimento). Estas suposições são inspiradas em Chick (1983) e em Ferreira e Michel $(1988,1991)$ e são compatíveis com Keynes $(1936) \cdot{ }^{16}$

Assim, considerando a concepção de curva de oferta agregada de Keynes (1936, p. 44) - para a economia como um todo, isto é, desprezando o subscrito "r" - temos $p=\frac{Z}{O}=\frac{\phi(N)}{\psi(N)}$, que dá origem a $Z=p O \cdot{ }^{17}$ Esta, por sua vez, pode ser reescrita em termos da elasticidade-preço da demanda, do salário nominal, do produto marginal do trabalho, do produto médio do trabalho e do nível de emprego. Isto significa que $Z=p O$ assume a forma $Z=\frac{\eta}{\eta-1} \cdot \frac{W}{P M g_{N}} \cdot P M e_{N} \cdot N$ ou

$$
Z=\frac{\eta}{\eta-1} \cdot \frac{W}{\psi^{\prime}(N)} \cdot \psi(N)
$$

cuja inclinação e curvatura são dadas respectivamente por

$$
\frac{d Z}{d N}=\frac{\eta}{\eta-1} \cdot W\left[1-\frac{\psi(N) \cdot \psi^{\prime \prime}(N)}{\left[\psi^{\prime}(N)\right]^{2}}\right]
$$

e

16 Ver, em especial, Chick (1983, p. 88), onde a autora sugere o caso mais geral e simples de concorrência imperfeita e a consequente relação entre preço, receita marginal e elasticidade-preço da demanda. Ferreira e Michel (1991, p. 176-178) usam uma notação ligeiramente diferente (e em termos desagregados) e consideram tanto o caso em que o preço esperado é função do nível de produto, que por sua vez é uma função do nível de emprego, quanto o caso em que o preço esperado dos insumos adquiridos pelo produtor depende da demanda por estes insumos (e dos diferentes valores possíveis para a elasticidade-preço desta demanda). Neste texto, consideramos a versão mais simples de Chick.

17 Para este resultado desprezamos o custo de uso.

18 A demonstração deste resultado está no Apêndice A. 


$$
\frac{d^{2} Z}{d N^{2}}=\frac{\eta}{\eta-1} \cdot W\left[\frac{2 \psi(N) \psi^{\prime \prime}(N) \psi^{\prime \prime}(N)}{\psi^{\prime}(N) \psi^{\prime}(N) \psi^{\prime}(N)}-\left(\frac{\psi^{\prime}(N) \psi^{\prime \prime}(N)+\psi(N) \psi^{\prime \prime \prime}(N)}{\psi^{\prime}(N) \psi^{\prime}(N)}\right)\right]
$$

Nesta formulação, mais geral, tanto a inclinação quanto a curvatura da função dependem da elasticidade-preço da demanda, do nível do salário nominal $W$ e das características da função de produção $\mathrm{O}=\psi(N)$, isto é, das hipóteses sobre os rendimentos físicos de escala - ou, mais precisamente, sobre a produtividade média $\psi(N) / N$ e a produtividade marginal do trabalho $\psi^{\prime}(N)$.

Assim, ao propor que a função oferta agregada é linear com uma inclinação dada pela recíproca do salário nominal (cf. KEYNES, 1936, nota 2, p. 55), Keynes supõe:

- que o mercado opera em concorrência perfeita, de modo que

$$
p=R M g \frac{\eta}{\eta-1}=1 \text {; }
$$

- que o produto marginal do trabalho é constante e igual à unidade (ou seja, que cada trabalhador adicional empregado produz uma unidade adicional de produto), de modo que $\psi^{\prime}(N)=1$ e $\psi^{\prime \prime}(N)=0$.

Neste caso, as funções $Z$ e $Z_{\mathrm{W}}(=Z / W$, a hipótese que Keynes utiliza na referida nota de rodapé) tomam as formas $Z=W \cdot \psi(N)$ e $Z_{\mathrm{W}}=\psi(N)$, respectivamente. No que diz respeito à inclinação e à curvatura, as suposições implícitas de Keynes resultam em $\mathrm{d} Z / \mathrm{d} N=W$ e $\mathrm{d}^{2} Z / \mathrm{dN}^{2}=0$ para a função $Z$, e $\mathrm{d} Z_{\mathrm{W}} / \mathrm{d} N=1$ e $\mathrm{d}^{2} Z_{\mathrm{W}} /$ $\mathrm{d} N^{2}=0$ para a função $Z_{\mathrm{W}}$, respectivamente.

Entretanto - e isso é importante -, para que a inclinação seja a recíproca do salário nominal, é preciso que se considere que Keynes tinha em mente não a função oferta agregada (conforme escreve de fato) e sim a sua inversa, isto é, a função na qual o nível de emprego é função de $Z$, quando $Z=D$, ou seja, a função que relaciona o nível de emprego à demanda efetiva na forma $N=\mathrm{F}(Z=D)$ ou $\mathrm{N}=\mathrm{F}\left(D^{\mathrm{EF}}\right)$. Tratase, portanto, da função emprego, cuja inclinação é $\frac{d N}{d D^{E F}}=\frac{1}{W} \cdot{ }^{19}$

Conclui-se que é preciso corrigir o texto de Keynes naquela nota de rodapé. No lugar de "the aggregate supply function is linear with a slope given by the recipro-

19 Evidentemente, para $D^{E F_{W}}=D^{E F} / W$ temos $\mathrm{dN} / \mathrm{d} D^{E F}{ }_{W}=1$. Agradeço o parecerista anônimo que chamou a atenção para o fato de esta expressão poder ser traduzida em termos da elasticidade do produto, que Keynes introduz no capítulo 20 da Teoria Geral. Ver Apêndice B. 
cal of the money-wage" deve-se ler "the employment function is linear with a slope given by the reciprocal of the money-wage".

Conforme se verá a seguir, este erro da Teoria Geral é o responsável pelo fato de as descrições da função emprego $N=\mathrm{F}(Z=D)$ propostas pelos autores analisados neste texto não terem sido bem sucedidas - ainda que o erro tenha sido detectado (mas não corrigido) por estes mesmos autores (e outros). ${ }^{20}$

\section{O Modelo Z-D de Victoria Chick}

O título do livro de Victoria Chick tem um duplo sentido que se perdeu na tradução para o português. A expressão "after" em Macroeconomics after Keynes não é apenas "após" cronologicamente, mas é também "segundo", isto é, "de acordo com Keynes". Trata-se, conforme o subtítulo, de uma reconsideração da Teoria Geral que procura "lançar uma nova luz sobre o livro de Keynes" e encorajar sua reintrodução no ensino de economia.

No que diz respeito ao princípio da demanda efetiva, Chick avalia que Keynes escolheu termos confusos e não os utilizou de forma coerente - a "armadilha semântica". Para a autora, os termos "demanda agregada" e "demanda efetiva" são muito semelhantes, mas referem-se a conceitos bem diversos. Além disso, "demanda agregada" pode ter dois significados diferentes.

Ela esclarece que - genericamente - a "demanda agregada" relaciona, de um lado, os gastos (que variam com a variação da renda) e, de outro, os níveis de emprego (associados aos diferentes níveis desta renda). Porém, os gastos podem ser interpretados como sendo a soma do consumo e do investimento planejados por parte dos consumidores e investidores ou como a estimativa (expectativa) da soma do consumo e do investimento, calculada pelos empresários quando decidem produzir (e contratar mão de obra). ${ }^{21}$

Por outro lado, ressalta que a "demanda efetiva" não é uma relação e sim um ponto sobre a curva de demanda agregada, que identifica o volume de produção que os empresários decidem produzir, avaliado ao preço demandado (pelos empresários) igual ao valor das vendas esperadas. Trata-se, segundo ela, de um "termo infeliz" - uma "armadilha semântica" a que Keynes não deu muita importância. (CHICK, 1983, p. 64).

20 Ver, por exemplo, os comentários de Dickson (1983, p. 245), Chick (1983, nota 9, p. 80), Hayes (2007, p. 750), Hartwig e Brady (2008, nota 2, p. 818).

21 Ferreira e Michel $(1988,1991)$ fazem a mesma observação e informam que esta dualidade já havia sido reconhecida por vários autores. 
A representação gráfica sugerida e adotada por Chick está reproduzida na Figura 1. A função demanda agregada (denominada $D^{e}$ para explicitar seu caráter expectacional) é côncava em relação à abscissa (que mede o nível de emprego) e não passa pela origem. Sua inclinação é determinada pela propensão marginal a consumir, que é inferior à unidade. A função toma o investimento como dado. Além disso, ela corta a função Z "por cima", em acordo com as figuras mais comuns do modelo $Z-D .^{22}$

Para Chick, a função demanda agregada é mais complexa do que a função oferta agregada. Uma das razões decorre dela representar as estimativas (expectativas) de vendas, o que consequentemente exige uma proposição sobre como estas expectativas são formadas. Outra razão deriva da necessidade de especificar a função em termos reais. Enquanto a primeira dificuldade é contornada com o pressuposto de que as expectativas de curto prazo são sempre cumpridas, a segunda é resolvida com o expediente de "deflacionar" os valores nominais pela unidade de salário (gerando $D_{\mathrm{w}}$ e $Z_{\mathrm{w}}$ respectivamente) - mas Chick alerta que isto só é possível quando não há inflação de preços nem variação de salários relativos.

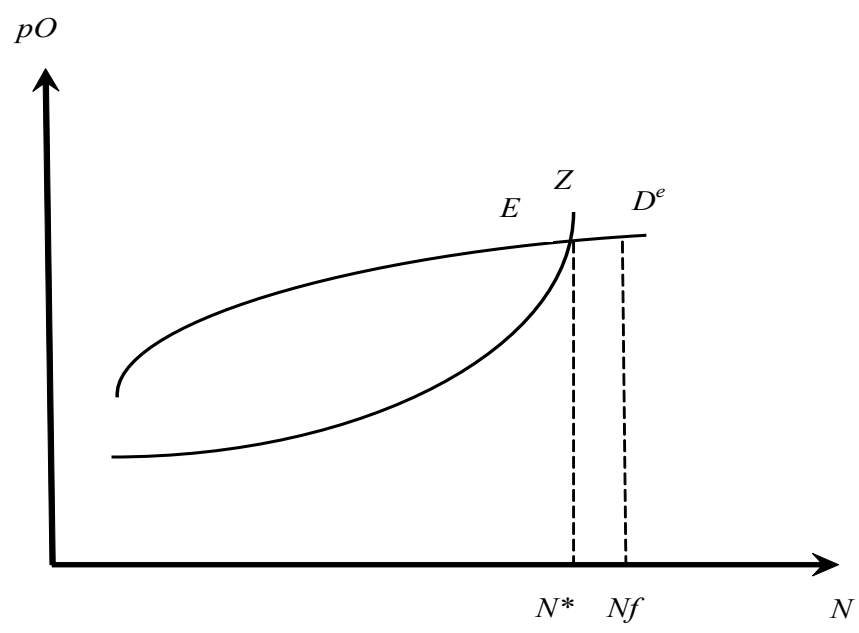

Figura 1 - Chick $\left(1983\right.$, p. 63) ${ }^{23}$

22 Além de ser inferior à unidade, a propensão a consumir não é fixa (situação na qual seria uma função linear). Diferentes hipóteses sobre a propensão (média e marginal) a consumir são discutidas por Hansen (1953) na construção do modelo da reta de $45^{\circ}$, no qual também a função Z é linear.

23 Notação da ordenada alterada de $P Q$ para $p O$. O mesmo vale para a Figura 2. 
A função $Z$, na versão de Chick, por sua vez, é convexa em relação à abscissa e tampouco passa pela origem. ${ }^{24}$ Sua forma é determinada pela função de produção, pelos custos de produção, pelo grau de monopólio e pela composição setorial do produto.

Quando da construção da função $Z$ na forma $Z=\frac{\eta}{\eta-1} \cdot \frac{W}{\psi^{\prime}(N)} \cdot \psi(N)$, Chick sugere que o produto marginal do trabalho é crescente a taxas decrescentes, mas também considera que pode ser constante (e igual ao produto médio). Evidentemente, a alternativa do produto marginal decrescente se justificaria numa situação de pleno emprego ou próxima disto.

Para Chick,

... the marginal product of labour is positive but declining at a constant or increasing rate: $\psi^{\prime}(N)>0, \psi^{\prime \prime}(N)<0, \psi^{\prime \prime \prime}(N) \geq 0$. When the production function has these properties, both $\psi(N) / N$ and $\psi^{\prime}(N)$ decline as $\mathrm{O}$ increases. Therefore $\psi(N) / N$ lies above $\psi^{\prime}(N)$ and falls less rapidly than $\psi^{\prime}(N)$ and $[\psi(N) / \mathrm{N}] / \psi^{\prime}(N)$ increases as $\mathrm{N}$ increases, giving the slope as indicated in [the] Figure. If we had assumed constant returns $\left[\psi(N) / N=\psi^{\prime}(N)\right]$, the function would be a straight line with the slope given by the wage rate. (CHICK, 1983, p. 66, notação adaptada).

O aspecto específico mais importante da interpretação de Chick está relacionado à sua proposição de que, embora o salário seja dado, ele pode assumir diferentes valores. Assim, para cada um destes valores, haverá uma função $Z_{\left(W_{i}\right)}$ correspondente - descritas no quadrante inferior da Figura 2.

Cada curva $Z_{\left(W_{i}\right)}$ tem um limite inferior que corresponde ao valor mínimo do preço de oferta necessário para que o empresário decida produzir, dado aquele nível de salário. À medida que este preço de oferta aumenta, e para o mesmo nível de salário, o nível de emprego aumenta. Isto justifica a inclinação positiva das curvas $Z_{\left(W_{i}\right)}$, enquanto a sua convexidade registra o pressuposto de que o produto marginal é decrescente a taxas crescentes.

O limite superior de cada curva $Z_{\left(W_{i}\right)}$, por sua vez, corresponde ao ponto em que se torna impossível aumentar o nível de emprego sem aumentar também o salário (por

24 A autora o justifica pelo fato de que, embora "seja verdade que não há produto se não houver emprego, o argumento não é suficiente" (CHICK, 1983, nota 10, p. 98). No entanto, ela não oferece qualquer outra explicação para esta característica da função - ou seja, seu argumento também não é suficiente. Além disso, o raciocínio aplicar-se-ia igualmente à função demanda. 
exemplo: se o salário é $W_{1}$, a quantidade máxima de emprego é $N_{1}$; se o salário é $W_{2}$, a quantidade máxima de emprego é $N_{2}$, etc...). Para Chick, o limite superior de cada curva $Z_{(W i)}$ representa o pleno emprego para aquele nível de salário e é determinado pela função oferta de trabalho $N^{S}$, que está descrita no quadrante superior da Figura 2. A junção destes diferentes pontos de pleno emprego dão origem à curva $Z_{N}$, uma espécie de curva $Z$ envoltória, que descreve a função oferta agregada para qualquer nível de salário. Vale ressaltar que, no ponto em que esta função $Z_{\mathrm{N}}$ intercepta a curva de demanda agregada $D^{\mathrm{e}}$ (o ponto de demanda efetiva), determina-se, segundo Chick, o nível de emprego de equilíbrio.

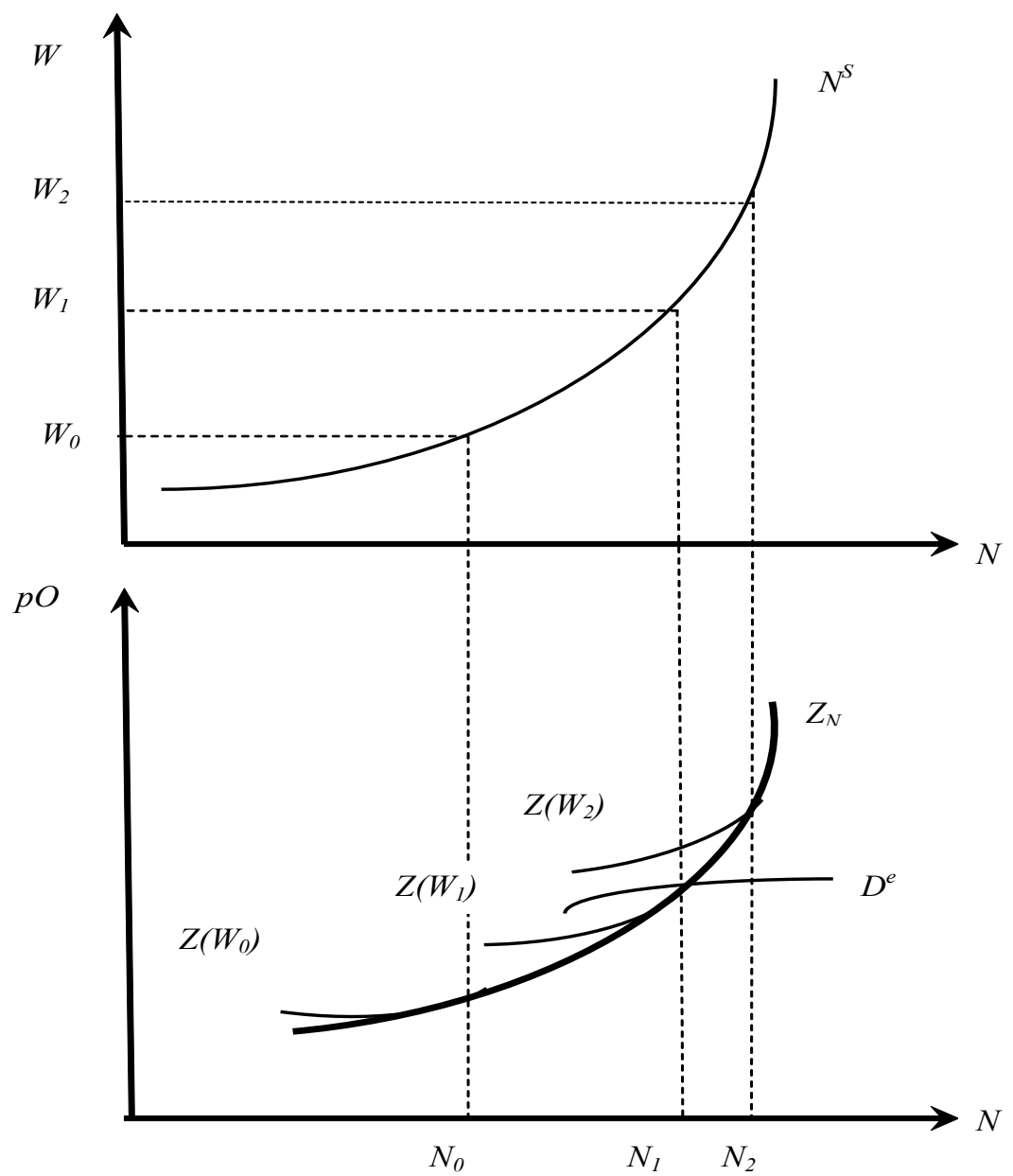

Figura 2 - Chick (1983, p. 93)

Uma observação importante de Chick é que esta função $Z_{N}$ pode ser "deflacionada" pela unidade de salário $\left(Z_{\mathrm{W}}=Z / W\right)$, gerando a função oferta agregada em termos 
reais. A autora argumenta que o cálculo de $Z_{\mathrm{W}}$ é necessário, pois, embora a função oferta agregada possa ser descrita em termos nominais, já que as firmas buscam lucros nominais, a função demanda agregada precisa ser descrita em termos reais, pois quem consome (ou investe) não tem por objetivo "gastar dinheiro" e sim obter bens. (CHICK, 1983, p. 51). Portanto, segundo ela, é preciso "traduzir" as funções, isto é, colocá-las nos mesmos termos (reais ou nominais) e, ao mesmo tempo, relacioná-las ao nível de emprego (e não ao nível de renda). Assim, a função $\frac{Z}{W}=Z_{W}=\frac{\eta}{\eta-1} \cdot \frac{P M e_{N}}{P M g_{N}} N=\frac{\eta}{\eta-1} \cdot \frac{\psi(N)}{\psi^{\prime}(N)}$ deixa de depender do salário $W-$ mas isso não altera sua forma convexa. Chick (1983, p. 70) argumenta que a convexidade de $Z$ (ou de $Z_{W}$ ) não conflita com a já mencionada formulação de Keynes (Teoria Geral, nota 2 , p. 55) de que a inclinação de $Z_{\mathrm{W}}$ é a unidade, pois Keynes supõe concorrência perfeita associada ao caso particular de rendimentos constantes. ${ }^{25} \mathrm{O}$ que ela não percebe é que a curva envoltória é uma espécie (incompleta) da função emprego de Keynes.

A crítica às concepções subjacentes à Figura 2 será feita na última seção deste texto.

\section{O Modelo Z-D de Rodolphe Ferreira e Philippe Michel}

A formalização do princípio da demanda efetiva proposta por Ferreira e Michel $(1988,1991)$ supõe concorrência perfeita, embora os autores destaquem que a análise keynesiana é aplicável a casos em que vigora a concorrência imperfeita no mercado de produto e/ou de fatores.

25 Como já visto, neste caso, temos $\mathrm{d} Z_{\mathrm{W}} / \mathrm{d} N=1$, o que está de acordo com a nota de rodapé da página 55 da Teoria Geral, reproduzida neste artigo. O argumento original da autora, no entanto, é bastante confuso, conforme ela mesma reconhece posteriormente. Ver Chick (1983, p. 70 e nota 9, p. 80) e sua réplica a Nevile (1992) em Chick (1992). Ver também Brady (2004b, 2006). 


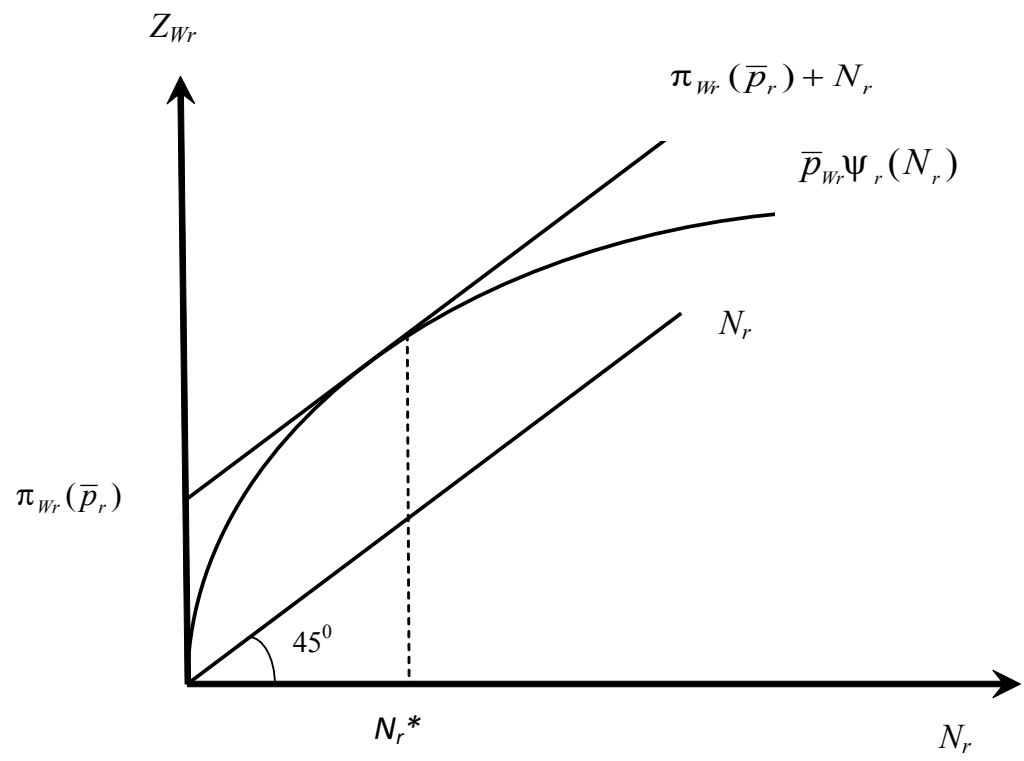

Figura 3 - Ferreira e Michel (1988, p. 255) ${ }^{26}$

Como Keynes, Ferreira e Michel definem o lucro como a diferença entre o rendimento esperado das vendas e o custo esperado da produção para diferentes níveis hipotéticos de emprego. Assim, considerando que $p$ é o nível esperado de preços e que o produto $\mathrm{O}$ depende da função de produção - ou seja, $\mathrm{O}=\psi(N)$ - o rendimento esperado da venda é dado por $p \mathrm{O}=p \psi(N)$. O custo de produção, por sua vez, é composto exclusivamente pela folha de salários, isto é, $W N .{ }^{27}$ Consequentemente, o lucro do produtor ou firma individual é dado por $\pi=p \psi(N)-W N$.

Na representação gráfica proposta por Ferreira e Michel, todas as funções estão medidas em unidades de salário.

Enquanto a função demanda agregada, medida em unidades de salários $p_{\mathrm{w}} \psi(N)$ - entendida como o rendimento que o empresário espera receber decorrente do emprego de $N$ homens -, é uma função côncava em relação à abscissa, o custo total $W N$, medido em unidades de salário, é $N(=W N / W)$ e está representado por

26 A notação da Figura 3 e da Figura 4 foi mantida conforme o original: níveis de preços $\bar{p}$ e $\overline{\bar{p}}$ e lucro $\pi$. Além disso, os autores consideram a desagregação setorial, designada pelo subscrito "r".

27 Em Ferreira e Michel (1991), os autores consideram que os custos são compostos não apenas pela folha de salários, mas também pelo custo de uso. Além disso, generalizando a suposição de concorrência imperfeita, substituem o preço esperado pelo conjunto de fatores que influenciam este preço. 
uma reta que parte da origem com inclinação de $45^{\circ}$. Além disso, considerando que o produtor maximiza o lucro $\pi_{\mathrm{W}}=p_{\mathrm{w}} \psi(N)-N$, a função que determina a máxima diferença entre $p_{\mathrm{w}} \psi(N)$ e $N$ é a tangente de inclinação de $45^{\circ}$ à função $D\left[=\left(p_{\mathrm{w}} \psi(N)\right]\right.$. A tangente é representada por $\pi_{\mathrm{W}}(p)+N$, que, na visão dos autores, descreve os rendimentos esperados que tornam compensatório contratar um dado nível de emprego. Esta é a definição da função oferta agregada $Z$ de Keynes e, portanto, a reta tangente é a função $Z$, cujo intercepto com a ordenada mede o lucro máximo esperado $\pi_{\mathrm{w}}(p)$, que é explicitamente dependente do nível de preços esperado $p$. É particularmente interessante destacar que, ao contrário do modelo $Z$ - $D$ de Chick, a função $Z$ de Ferreira e Michel não intercepta a função $D$, mas, por ser linear, apenas a tangencia. Voltaremos a este ponto mais adiante e na última seção.

Considerando que a cada nível possível de preços esperados $(\bar{p}$ e $\overline{\bar{p}})$ corresponde um par específico de funções - a função $D$ ou rendimento esperado $p_{\mathrm{w}} \psi(N)$ e a função rendimento necessário esperado $\pi_{\mathrm{W}}(p)+N$ que a tangencia -, os autores sugerem que é possível desenhar uma curva que reúna os respectivos pontos de tangência. Esta curva está descrita na figura a seguir por $\phi(N)$ ou, em termos desagregados, por $\phi_{\mathrm{r}}\left(N_{\mathrm{r}}\right)$.

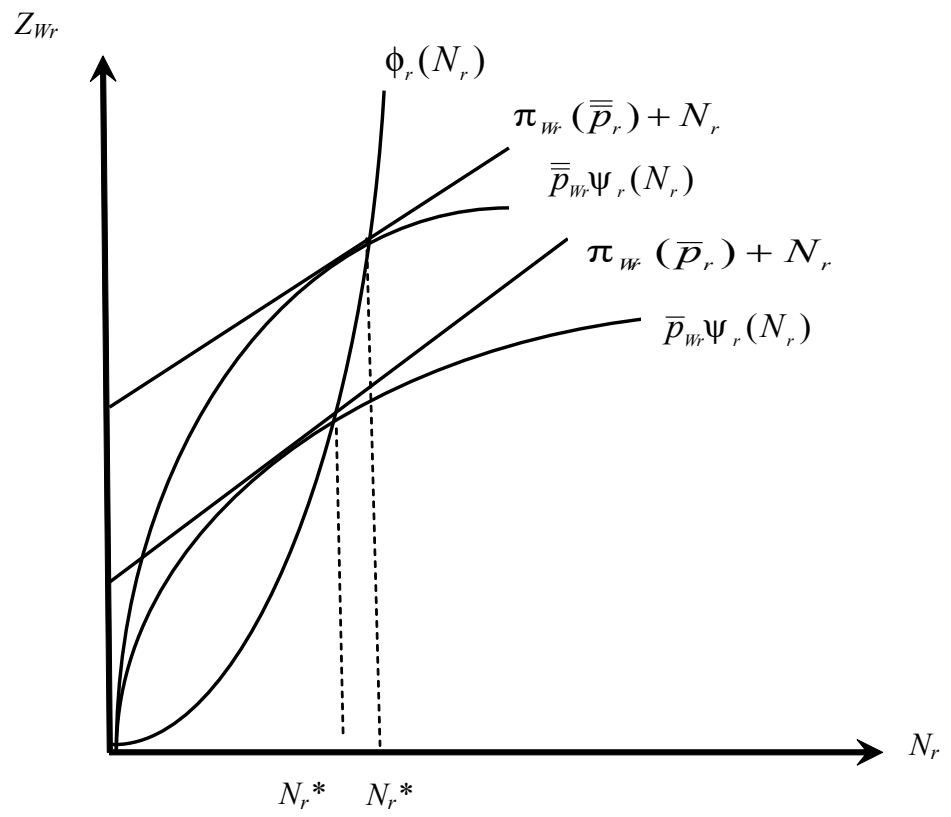

Figura 4 - Ferreira e Michel (1988, p. 259) 
É preciso observar que o símbolo $\phi$ escolhido pelos autores para descrever a curva que reúne os pontos de tangência é problemático, pois a descrição algébrica de $\phi(N)$ é a da função oferta agregada $Z$, enquanto a descrição em prosa (e gráfica) de $\phi(N)$ é a da curva de oferta agregada, que reúne os pontos de tangência entre $Z$ e $D$.

Segundo os autores, a curva $\phi(N)$

is simply a projection on the $\left(N_{r}, Z_{\mathrm{w}}\right)$ plane of the locus of potential demand points, that is to say, of the intersection of the expected proceeds plane and the required proceeds plane which lie in the $\left(N_{r}, Z_{\mathrm{wr}}, p\right)$ space where the third dimension corresponds to the expected price $p$. (FERREIRA; MICHEL, 1988, p. 258-259).

Em última análise, trata-se da curva de oferta agregada - que é a inversa da função emprego $N=\mathrm{F}(Z=D)$-, mas os autores não parecem se dar conta disto. Apenas no texto seguinte (FERREIRA; MICHEL, 1991, nota 3, p. 160-1) é que reconhecem que a curva que Keynes descreve, como tendo uma inclinação que é a recíproca do salário nominal, é de fato a função emprego, inversa da função oferta agregada. Trata-se, segundo os autores, de um ato falho, a "slip of the pen".

\section{O Modelo Z-D de Michael Brady}

Brady parece ter razão ao apontar que quase todos os intérpretes de Keynes se restringem à formalização inicial apresentada no capítulo 3 da Teoria Geral - com algumas incursões ao capítulo 10, sem reconhecer que a Teoria Geral se desenvolve por meio de um modelo que tem uma representação algébrica (fornecida por Keynes) passível de representação gráfica. A tese de Brady vai além: para ele, Keynes apresenta dois modelos - ou melhor, duas variações de um mesmo modelo. O primeiro é o "modelo $Z$-D", introduzido de forma resumida no terceiro capítulo da Teoria Geral e desenvolvido nos capítulos 19, 20 e 21. O segundo é o "modelo $Y^{\prime \prime}$ (da reta de $45^{\circ}$ ) dos capítulos 6 e 10 .

Brady também acusa estes autores de, por não darem a devida importância aos capítulos 19, 20 e 21 da Teoria Geral, não serem capazes de distinguir a função oferta agregada (a função $Z$ ) da curva de oferta agregada (o "locus" de intersecções entre $D$ e $Z$ ). A seu ver, isto explica o surgimento e a permanência da "indústria do 'o que é que Keynes quis realmente dizer'" [the "what did Keynes really mean" industry]. 
Brady reconhece, no entanto, que a formulação algébrica fornecida por Keynes está dispersa pelo livro e não está acompanhada de suas respectivas deduções. Estas deduções são justamente os temas dos vários artigos e ensaios que escreveu sobre o assunto, dentre os quais três são particularmente importantes (além dos mencionados anteriormente). O primeiro é o artigo intitulado "The mathematical development of Keynes's aggregate supply function in the General Theory" (BRADY, 1990), que serviu de base para a sistematização da formalização algébrica apresentada no presente texto. O segundo é o artigo "A comparison-contrast of J. M. Keynes' mathematical modeling approach in the General Theory with some of his General Theory interpreters, especially J. E. Meade" (BRADY, 1996), pois, além de apresentar suas críticas a vários intérpretes, é onde Brady apresenta uma descrição gráfica da Teoria Geral (o seu modelo $Z-D$ ), reproduzida (em versão simplificada) na Figura $5 .{ }^{28}$

A derivação algébrica que apresentamos neste texto seguiu, em linhas gerais, a contribuição de Brady e, por este motivo, não é necessário repeti-la. Um resumo é suficiente (e necessário) para interpretar sua proposta de "cruz" keynesiana na versão $Z-D$, descrita no quadrante superior da Figura 5.

Para Brady, dado que tanto a função demanda agregada quanto a função oferta agregada são descritas em termos de preços esperados, a cada nivel de preços esperados $p$ corresponde um par função demanda agregada ( $A D$ - aggregate demand) e função oferta agregada ( $A S F$ - aggregate supply function) diferente, assim como um nível diferente de lucro $P$ e portanto de emprego $N .^{29}$

As funções demanda agregada são côncavas em relação à abscissa (que mede o nível de emprego) e as funções oferta agregada são lineares, com um ângulo de $45^{\circ}$, representando o pressuposto de concorrência perfeita e rendimentos constantes de escala. A reta que passa pela origem representa a identidade $Y_{\mathrm{W}} \equiv \mathrm{C}_{\mathrm{W}}+I_{\mathrm{W}}$. Os valores na ordenada são todos "deflacionados" pela unidade salarial.

28 O terceiro artigo intitula-se "A mathematical proof of Keynes' general case" (BRADY, 2002) e nele o autor incorpora o caso em que o mercado de trabalho sofre restrições de demanda que ocorrem no mercado de bens e serviços. Por razões de espaço, não podemos desenvolver o argumento. Sucintamente, trata-se de considerar o mercado de bens separadamente, distinguindo bens de consumo dos bens de investimento de modo a generalizar o modelo agregado para o caso de um modelo bissetorial.

29 Vale notar que esta descrição é semelhante à de Chick, que, como vimos, considera uma família de funções $Z\left(W_{i}\right)$, onde cada "i" representa um dado nível de salário. Mas, como será discutido na última seção deste texto, há diferenças importantes entre as construções de Chick e de Brady. 
$p_{W} O=D_{W}=Z_{w}$

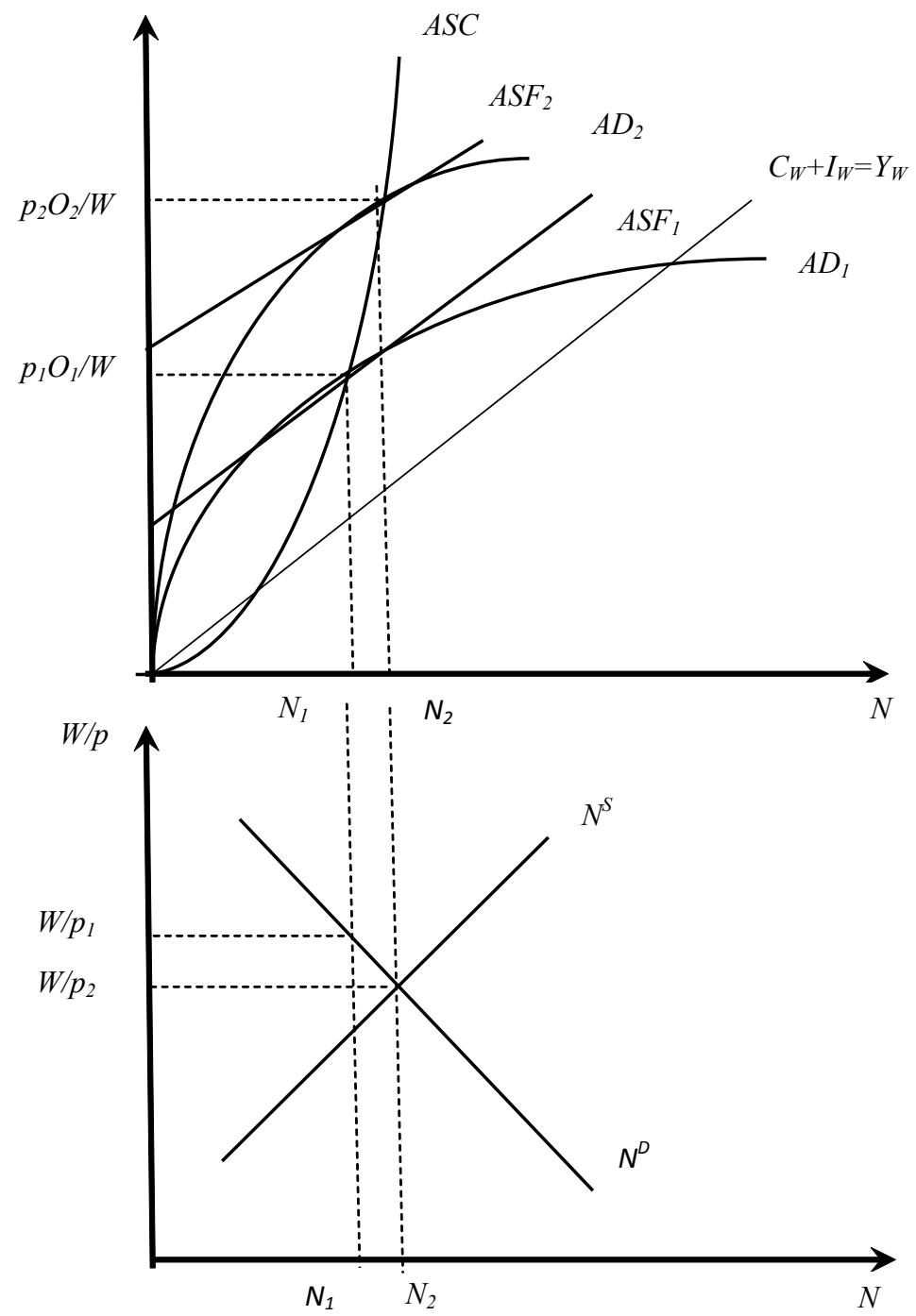

Figura 5 - Brady $(1996, \text { p. 135) })^{30}$

Assim, supondo níveis diferentes de preços esperados $p^{\mathrm{e}}$, a Figura 5 descreve pares de funções de demanda agregada $(A D)$ e de oferta agregada $(A S F)$, cada par correspondendo a um destes níveis de preços. Os pontos de intersecção - ou mais precisamente, de tangência - entre a demanda agregada e a oferta agregada de cada

30 A Figura original foi editada, retirando-se as informações que dizem respeito ao modelo bissetorial mencionado anteriormente e que não será tratado aqui. 
par representam diferentes níveis de demanda efetiva, cada um correspondente a um nível de preços. A curva traçada de forma a unir estes pontos é a curva de oferta agregada - ASC (aggregate supply curve) - ou o locus das igualdades $D=Z$, que é idêntica à curva $\phi(N)$ na Figura 4 de Ferreira e Michel, e que corresponde à inversa da função emprego $N=\mathrm{F}(Z=D)$, o que Brady não percebe.

Uma característica distintiva desta contribuição, ausente na de Ferreira e Michel e passível de comparação com a de Chick, é o quadrante inferior da Figura 5, que representa o mercado de trabalho. Embora seja equivalente ao quadrante superior da Figura 2 de Chick, há diferenças evidentes a serem destacadas, o que será feito na próxima seção.

Antes, porém, vale ressaltar que a representação gráfica de Brady mostra explicitamente que a reta de $45^{\circ}$ do quadrante superior, além de representar a identidade $Y_{\mathrm{W}}=\mathrm{C}_{\mathrm{W}}+I_{\mathrm{W}}$ (os componentes da renda, isto é, consumo e investimento medidos em unidades de salário), não é necessariamente uma representação da "teoria neoclássica". A reta de $45^{\circ}$ pode também ser interpretada como uma função oferta agregada $Z$, desde que se considere que a concorrência é perfeita e que os rendimentos de escala são constantes. Em particular, a reta com inclinação de $45^{\circ}$, que passa pela origem, representa um dado nível de preço esperado, que, na notação de Brady, seria $p_{0}\left(\operatorname{com} p_{0}<p_{1}\right)$. Tomando emprestadas as palavras de Ferreira e Michel (1988, p. 261), ela é "perfeitamente adequada para o ataque à lei de Say" - e portanto não é neoclássica. ${ }^{31}$

\section{Síntese}

No texto acima, explicitamos as definições de demanda agregada, oferta agregada, demanda efetiva, função de produção, função emprego e curva de oferta agregada apresentadas por Keynes na Teoria Geral, e desenvolvemos a formulação algébrica da função oferta agregada $Z$, demonstrando que sua forma (linear ou convexa) depende das hipóteses relativas tanto à estrutura de mercado quanto aos rendimentos físicos de escala (ou produtividade do trabalho).

Corrigimos a redação da nota de rodapé da página 55 da Teoria Geral, pois a função que Keynes descreve como sendo linear com uma inclinação dada pela recíproca do salário nominal é a função emprego $N=F\left(D^{E F}\right)$ e não a função oferta agregada

31 Brady (em e-mail enviado aos autores em 27 de setembro de 2007) confirma concordar com a conclusão de Ferreira e Michel - mas ressalta que, ao contrário deles (e outros), não se considera um "intérprete" de Keynes. Seu argumento é que não há o que ser interpretado, pois todas as equações necessárias para a descrição gráfica que apresenta foram fornecidas por Keynes, embora não plenamente desenvolvidas, e estão na Teoria Geral. 
$Z=\phi(N)$, como ele escreveu. A função emprego, por sua vez, é a inversa da curva de oferta agregada - isto é, a que reúne os pontos de demanda efetiva descrita como $\phi(N)$ na Figura 4 (de Ferreira e Michel) ou como ASC na Figura 5 (de Brady) - e não da função oferta agregada. O erro de Keynes parece decorrer das condições específicas que ele adotou quanto à elasticidade-preço da demanda (igual ao infinito) e rendimentos (constantes) de escala, e apenas as condições mais gerais discutidas neste texto é que permitiram fazer as distinções necessárias. Aceita a correção, pode-se considerar encerrada uma parte da "indústria do 'o que é que Keynes quis realmente dizer'” e avançar no desenvolvimento de um corpo teórico formal keynesiano conforme sugestões apresentadas ao final deste artigo - ou outras.

Também descrevemos as versões gráficas do modelo $Z$ - $D$ de Chick, de Ferreira e Michel e de Brady, destacando as características específicas de cada uma destas três formulações.

As três contribuições analisadas admitem a concorrência não perfeita, mas a de Victoria Chick é a única entre elas que supõe explicitamente hipóteses menos restritivas sobre os rendimentos de escala, o que leva a uma função $Z$ não linear. Consideramos que estas suposições geram um instrumental mais genérico. Os demais autores analisados neste texto reconhecem estas possibilidades na descrição algébrica da função $Z$, mas abrem mão delas ao apresentar a descrição gráfica com funções $Z$ lineares.

Outra característica importante da contribuição de Chick é a inclusão do mercado de trabalho no escopo de análise e a consideração de que, a cada nível de salário, há uma determinada função oferta agregada $Z_{\mathrm{W}}$, cujo limite inferior corresponde ao valor mínimo do preço de oferta necessário para que o empresário decida produzir (dado aquele nível de salário) e cujo limite superior corresponde ao nível de pleno emprego para o dado nível de salário. As funções $Z_{W_{i}}$ são positivamente inclinadas para descrever a suposição de que o nível de emprego aumenta acompanhando a elevação do preço de oferta (dado o nível de salário), e convexas para descrever a suposição de rendimentos crescentes a taxas decrescentes.

A formulação de Chick, no entanto, tem dois problemas. O primeiro refere-se ao fato de a sua função demanda agregada $D$ não ser sensível ao nível de salário, já que cresce apenas em função do aumento do nível de emprego. Ou seja, ao contrário das funções $Z_{\mathrm{Wi}}$ (que se deslocam para cima quando o salário aumenta), a função $\mathrm{D}$ não se move. Seria de se esperar que, com salários mais altos, as funções demanda agregada também se deslocassem para cima. O segundo problema, talvez mais sério, é a suposição de que o nível de emprego é determinado pela função oferta de trabalho ( $N^{S}$ no quadrante superior da Figura 2), agravado pela ausência de qualquer 
referência gráfica à demanda por trabalho, especialmente no que diz respeito à determinação do nível de emprego.

Uma justificativa possível (mas incompleta), para este lapso aparente de Chick, é que os níveis de emprego marcados nas abscissas dos dois quadrantes são os de pleno emprego - e, neste caso, faz sentido que sejam determinados (ou "delimitados") pela oferta de trabalho. A ausência da função demanda por trabalho poderia indicar que ela está representada (ou "pressuposta") na função $Z$, que descreve - na concepção original de Keynes - os níveis de emprego que os empresários consideram que vale a pena contratar. Em todo caso, estas justificativas são conjecturas, pois a autora não trata destas questões.

Os textos de Ferreira e Michel, por sua vez, têm o mérito de considerar várias formas de concorrência imperfeita (que, no entanto, não estão desenvolvidas, mas apenas indicadas). Os autores são mais restritivos no que diz respeito à descrição gráfica da função $Z$ (que representa apenas a hipótese de rendimentos constantes de escala), com o que não há efetivamente "intercepto" entres a funções $Z$ e $D$, mas apenas tangência. Isto, no entanto, não prejudica a construção de uma curva de oferta agregada como o locus que reúne os diferentes pontos de demanda efetiva, os quais, por sua vez, estão associados, cada um, a um dado nível de preços esperados. Assim, diferentemente de Chick, cada função $Z$ corresponde a um dado nível de preços (e não de salários), e a cada nível de preços corresponde também uma função $D$ (que, não é exagero repetir, não é sensível ao nível de salários na formulação de Chick).

A formulação de Ferreira e Michel tem, porém, duas lacunas importantes. A primeira refere-se à ausência de qualquer menção ao mercado de trabalho e a segunda diz respeito ao fato de não terem ressaltado que a inversa da função que reúne os pontos de tangência entre $Z$ e $D$ - isto é, a curva de oferta agregada - é a função emprego de Keynes.

Finalmente, o modelo $Z$ - $D$ de Brady também supõe apenas a hipótese de rendimentos constantes de escala, mas tem o mérito de considerar que não somente a demanda agregada e a oferta agregada sejam sensíveis ao nível de preços (como Ferreira e Michel) como também a demanda por trabalho - que não se confunde com a função $Z$ como parece ser o caso de Chick. Deste ponto de vista, é uma versão mais acabada e mais fiel à concepção de Keynes, já que explicita que é demanda por trabalho que determina o nível de emprego - e não a oferta de trabalho, como parece indicar Chick. Por outro lado, Brady parece não se dar conta de que sua curva de oferta agregada (que tanto insiste em distinguir da função oferta agregada) nada mais é do que a inversa da função emprego de Keynes. 
Nenhum dos autores analisados neste texto reconhece que suas próprias contribuições chegaram muito perto da descrição gráfica da função emprego de Keynes. Porém, as três versões têm o mérito de demonstrar que é possível descrever o conceito de demanda efetiva através de um diagrama inspirado no modelo $Z$ - $D$. Além disso, mostram que é possível considerar suposições menos restritas que as utilizadas por Keynes. Entre elas, destacam-se:

- concorrência imperfeita, de modo que $p \neq R M g$ ou $\frac{\eta}{\eta-1} \neq 1$;

- diferentes alternativas de rendimentos de escala: decrescentes (a taxas crescentes, constantes ou decrescentes), crescentes (a taxas crescentes, constantes ou decrescentes) e constantes - ressaltando-se que a dificuldade de dar sentido econômico às suposições de rendimentos decrescentes a taxas decrescentes e a de rendimentos crescentes a taxas crescentes;

- diferentes níveis hipotéticos de salário nominal (à la Chick) e seus efeitos sobre a demanda agregada, a oferta agregada (e portanto sobre a demanda efetiva), bem como sobre a demanda por trabalho (e eventualmente sobre a oferta de trabalho);

- diferentes níveis hipotéticos de preços (à la Ferreira e Michel, e Brady) e seus efeitos sobre a demanda agregada, a oferta agregada (e, portanto, sobre a demanda efetiva), bem como sobre a demanda por trabalho (e eventualmente sobre a oferta de trabalho).

Obviamente, outras características são possíveis, tais como diferentes combinações de variações do nível de preços e do salário nominal - em proporções iguais ou diferentes - e seus efeitos, por meio do resultante salário real, sobre a demanda agregada, a oferta agregada (e portanto sobre a demanda efetiva), bem como sobre a demanda por trabalho e a oferta de trabalho. No entanto, as listadas acima nos parecem suficientes.

\section{Referências}

AMADEO, E. J. S. Keynes's principle of effective demand. London: Edward Elgar, 1989.

AMBROSI, G. M. Keynes and the 45-degree cross. Journal of Post Keynesian Economics, v. 3, p. 503-509, 1981.

ARTHMAR, R.; BRADY, M. E. Patinkin, Keynes and the Z curve. History of Economic Ideas, v. 17, p. 127-146, 2009. 
ASIMAKOPULOS, A. Keynes's theory of effective demand revisited. Australian Economic Papers, v. 21, p. 18-36, 1982.

BRADY, M. E. The mathematical development of Keynes's aggregate supply function in the general theory. History of Political Economy, v. 22, p. 167-172, 1990.

. A comparison-contrast of J. M. Keynes' mathematical modeling approach in the general theory with some of his general theory interpreters, especially $\mathrm{J}$.

E. Meade. History of Economics Review, v. 25, p. 129-159, 1996.

. A study of the 1954-1956 Economic Journal aggregate supply function debate and the post-keynesian theoretical wrong turn. Indian Journal of Applied Economics, v. 8, p. 57-74, 1999a.

. A note on Don Patinkin's misspecification of Keynes's consumption function and misinterpretation of Keynes' elasticity analysis in chapter 10 of the general theory. Indian Journal of Applied Economics, v. 8, 147-152, $1999 \mathrm{~b}$.

A mathematical proof of Keynes' general case. International Journal of Applied Economics and Econometrics, v. 10, p. 422-430. 2002.

. Essays on J. M. Keynes and.... Xlibris Corp., 2004.

. The role of mathematical illiteracy in the controversy over J. M. Keynes' general theory - the 'what did Keynes really mean' debate. In: on J. M. Keynes and.... Xlibris Corp., 2004, p. 347-378, 2004a. Essays

. J.M. Keynes' theory of effective demand - correcting the mathematical errors of P. Davidson, V. Chick, J. Nevile, D. Fusfeld et al. In: J. M. Keynes and.... Xlibris Corp., 2004, 2004b. p. 463-490. . Essays on

. Correcting the mathematical errors of E. Roy Weintraub, A. Leijonhufvud, P. Wells, and D. Patinkin in history of political economy concerning Keynes' employment function from 1974-1989. In: and.... Xlibris Corp., 2004, 2004c. p. 524-532. . Essays on J. M. Keynes

. A guide for economists who are having trouble reading chapter 3 of J.M. Keynes' General Theory. In: . The applied mathematics of J.M. Keynes' theory of effective demand in the general theory: correcting the mathematical errors of the economics profession. Xlibris Corporation, 2006. p. 129-136.

CASAROSA, C. Un contributo all'analisi dei fondamenti microeconomici della teoria keynesiana della domanda effettiva. Rivista di Politica Economica, v. 11, p. 1371-409, 1978.

. The microfoundations of Keynes's aggregate supply and expected demand analysis. Economic Journal, v. 361, p. 188-194, 1981.

. Aggregate supply and expected demand analysis in Keynes' General Theory: an essay on the micro-foundations. In: BARANZINI, M. (Ed.). Advances in economic theory. London: Blackwell, 1982. p. 67-79.

. The microfoundations of Keynes's aggregate supply and expected demand analysis: a reply. Economic Journal, v. 94, p. 941-5, 1984. 
CHICK, V. Macroeconomics after Keynes: a reconsideration of the general theory. Oxford: Philip Alan. 1983.

A comment on John Nevile's notes on aggregate supply. Journal of Post Keynesian Economics, v. 15, p. 261-262, 1992.

DAVIDSON, P. More on aggregate supply function. Economic Journal, v. 72, p. 452-457, 1962.

. Patinkin's interpretation of Keynes and the Keynesian cross. History of Political Economy, v. 21, p. 549-453, 1989a.

. Corrected version of Patinkin's interpretation of Keynes and the Keynesian cross. History of Political Economy, v. 21, p. 737-741, 1989b.

.; SMOLENSKY, E. Aggregate supply and demand analysis. London: Harper \& Row, 1964.

DE JONG, F. J. Supply functions in Keynesian economics. Economic Journal, v. 64, p. 3-24, 1954a.

. Keynes and supply functions: a rejoinder. Economic Journal, v. 64, p. 840$842,1954 b$.

. Keynes and supply functions: second rejoinder with a note on the concept of monetary equilibrium. Economic Journal, v. 65, p. 479-484, 1955. 1956.

DICKSON, H. How did Keynes conceive the entrepreneurs'motivation? Notes on Patinkin's hypothesis. History of Political Economy, v. 15, p. 229-247, 1983.

DILLARD, D. The Economics of John Maynard Keynes - The theory of a monetary economy. New York: Prentice-Hall, 1948.

FERREIRA, R. S.; MICHEL, P. Reflections on the microeconomic foundations of the Keynesian aggregate supply function. In: BARRERE, A. (Ed.). The foundation of Keynesian analysis. London: Macmillan, 1988. p. 251-262.

Keynes' Aggregate Supply Function and the Principle of Effective Demand. Recherches Économiques de Louvain, v. 57, n. 2, p. 159-187, 1991.

FUSFELD, D. R. Keynes and the Keynesian cross: a note. History of Political Economy, v. 17, p. 385-389, 1985.

. Keynes and the Keynesian cross: reply to Don Partinkin. History of Political Economy, v. 21, p. 545-547, 1989.

HANSEN, A. H. A guide to Keynes. New York: Mc-Graw-Hill, 1953.

HARTWIG, J. Keynes vs the post Keynesians on the principle of effective demand. European Journal of the History of Economic Thought, v. 14, p. 725-739, 2007. 
.; BRADY, M. E. Comment: Hayes on Z. Cambridge Journal of Economics, v. 32, p. 815-819, 2008.

HAWTREY, R. G. Keynes and supply functions. Economic Journal, v. 64, p. 834839, 1954.

. Keynes and supply functions - a further note. Economic Journal, v. 66, p. 482-484, 1956.

HAYES, G. M. Keynes's Z function, heterogeneous output and marginal productivity. Cambridge Journal of Economics, v. 31, p. 741-53, 2007.

. Keynes's Z function - a reply to Hartwig and Brady. Cambridge Journal of Economics. v. 32, p. 811-814, 2008.

HENNEBERRY, B.; WITTE, J. G. Keynes' employment function reexamined. History of Political Economy, v. 8, p. 428-434, 1976.

HICKS, J. R. Mr. Keynes and the 'classics': a suggested interpretation. Econometrica, v. 5, p. 147-159, 1937.

KEYNES, J. M. The general theory of employment, interest and Money. London: Macmillan Press Ltd., 1936.

KING, J. E. Aggregate supply and demand analysis since Keynes: a partial history. Journal of Post Keynesian Economics, v. 17, p. 3-32, 1994.

KLEVORICK, A. K. A note on a Keynesian aggregate employment function. International Economic Review, v. 7, p. 226-230, 1996.

KOENIG, G. Les fondements microéconomiques du principe de la demande effective. Revue Économique, v. 31, p. 430-464, 1980.

. Le concept keynesien de cout d'usage et les previsions du producteur. Revue Économique, v. 37, p. 697-722, 1986.

KOOROS, A. Keynes' aggregate supply function - a comment. Economic Journal, v. 71, p. 849, 1961.

LEIJONHUFVUD, A. Keynes employment function: comment. History of Political Economy, v. 6, p. 164-170, 1974.

MARTY, A. The aggregate supply function. Metroeconomica, v. 11, p. 179187,1959 .

. A geometrical exposition of the Keynesian supply function. Economic Journal, v. 71, p. 560-565, 1961.

. The aggregate supply function once again. Economic Enquiry, v. 19, p. 350$351,1981$.

NEISSEN, H. Keynes' aggregate supply function - further comments. Economic Journal, v. 71, p. 850-852, 1961.

NEVILE, J. Notes on Keynes's aggregate supply curve. Journal of Post Keynesian Economics, v. 15, p. 255-260, 1992. 
PARRINELLO, S. The price level implicit in Keynes's effective demand. Journal of Post Keynesian Economics, v. 3, p. 63-87, 1980.

PASINETTI, L. L. The principle of effective demand. In: HARCOURT, G. C.; RIA$\mathrm{CH}, \mathrm{R} . \mathrm{A}$. (Ed.). A 'second edition' of the general theory. London: Routledge, 1997. p. 93-104. v. I.

PATINKIN, D. Involuntary unemployment and the Keynesian supply function. Economic Journal, v. 59, p. 360-83, 1949.

Keynes' monetary thought: a study of its development. History of Political Economy, v. 8, p. 1-150, 1976.

. The aggregate supply function: a correction. History of Political Economy, v. 9, p. 156-9, 1977.

. Keynes's aggregate supply function: a plea for common sense. History of Political Economy, v. 10, p. 577-596, 1978.

. A study of Keynes' theory of effective demand. Economic Enquiry, v. 17, p. 155-176, 1979.

. A critique of Keynes' theory of effective demand. In: Anticipations of the general theory? And other essays on Keynes. $2^{\text {nd }}$ ed. Chicago: University of Chicago Press, 1984. p. 123-162.

. Keynes and the Keynesian cross: a further note. History of Political Economy, v. 21, p. 537-544, 1989.

ROBERTS, D. L. Patinkin, Keynes, and aggregate supply and demand analysis. History of Political Economy, v. 10, p. 549-576, 1978.

ROBERTSON, D. H. Keynes and supply functions. Economic Journal, v. 66, p. 485-487, 1956.

; JOHNSON, H. G. Keynes and supply functions. Economic Journal, v. 65, p. 474-478, 1955.

SOPER, C. S. The supply curve in Keynesian economics. South African Journal of Economics, v. 24, p. 1-8, 1956.

TARSHIS, L. The elements of economics: an introduction of the theory of price and employment. Boston: Houghton Mifflin, 1947.

. The aggregate supply function in Keynes's general theory. In: BOSKIN, M. (Ed.). Economics and human welfare: essays in honour of Tibor Scitovsky. New York: Academic Press, 1979. p. 361-92.

TORR, C. S. W. Microfoundations for Keynes's point of effective demand. South African Journal of Economics, v. 49, p. 334-348, 1981.

. The microfoundations of Keynes's aggregate supply and expected demand analysis: a comment. Economic Journal, v. 94, p. 936-940, 1984.

. The dual role of user cost in the derivation of Keynes's aggregate supply function. Review of Political Economy, v. 4, p. 1-17, 1992. 
VEENDORP, E. C. H.; WERKEMA, H. G. Mr. Well's aggregate supply function: a comment. Economic Journal, v. 71, p. 634-636, 1961.

VICKERS, D. Aggregate supply and the producer's expected demand curve. Journal of Post Keynesian Economics v. 10, p. 84-104, 1987.

WEINTRAUB, E. R. Income and Employment Analysis, New York, Pitman, 1951.

. The microfoundations of aggregate demand and supply, Economic Journal, v. 67, p. $455-470,1957$.

. Classical $45^{0}$ Keynesianism: a plea for its abandonment. In: Classical Keynesianism. Monetary theory and the price leve. Philadelphia: Chilton, 1961. p. $1-25$.

. Keynes employment function: comment. History of Political Economy, v. 6, p. 162-164, 1974.

WELLS, P. Keynes's aggregate supply function: a suggested interpretation. Economic Journal, v. 70, p. 536-542, 1960.

. A further comment. Economic Journal, v. 71, p. 636-637, 1961.

. Aggregate supply and demand: an explanation of chapter III of the 'General Theory'. Canadian Journal of Economics and Political Sciences, v. 28, p. 585590, 1962.

. Keynes's dynamic disequilibrium theory of employment. Quarterly Review of Economics and Business, v. 13, p. 89-93, 1973.

. Keynes employment function. History of Political Economy, v. 6, p. 158162, 1974.

. In review of Keynes. Cambridge Journal of Economics, v. 2, p. 315-325, 1978.

\section{Apêndice A - A Equação da Função $Z=p O$}

Considere uma estrutura de mercado em concorrência não perfeita em que $R M g=\frac{d(p O)}{d O}=p \frac{d O}{d O}+O \frac{d p}{d O}=p+O \frac{d p}{d O}=p\left(1-\frac{1}{\eta}\right)$, e em que a elasticidade-preço da demanda é dada por $\eta=-\frac{\frac{d O}{O}}{\frac{d p}{p}}=-\frac{d O}{d p} \frac{p}{O} \neq 1$. Portanto, $p=\frac{\eta}{\eta-1} R M g$.

Considere também que, no curto prazo, a mão de obra é o único fator de produção variável e que o salário nominal é fixo mesmo quando há variações no volume de 
emprego contratado (e consequentemente no volume de produto produzido), de modo que $\frac{d W}{d O}=0$.

Portanto, $C M g_{N}=\frac{d(N W)}{d O}=N \frac{d W}{d O}+W \frac{d N}{d O}=0+W \frac{d N}{d O}=W \frac{1}{P M g_{N}}$, onde $P M g_{N}=\frac{d O}{d N}$.

A condição de maximização do lucro exige $R M g=C M g$ e, portanto, $R M g=W \frac{1}{P M g_{N}}$.

Além disso, $P M e_{N}=\frac{O}{N}$ e, portanto, $O=P M e_{N} \cdot N$.

Fazendo as devidas substituições em $Z=p O$, chega-se a $Z=\frac{\eta}{\eta-1} \cdot \frac{W}{P M g_{N}} \cdot P M e_{N} \cdot N$.

Finalmente, substituindo $P M g_{N}=\frac{d O}{d N}$ por $\psi^{\prime}(N)$ e $P M e_{N}=\frac{O}{N}$ por $\frac{\psi(N)}{N}$, lembrando que $O=\psi(N)$ representa a função de produção, temos que $Z=\frac{\eta}{\eta-1} \cdot \frac{W}{P M g_{N}} \cdot P M e_{N} \cdot N$ pode ser escrita na forma $Z=\frac{\eta}{\eta-1} \cdot \frac{W}{\psi^{\prime}(N)} \cdot \psi(N)$.

Considerando a inclinação dada por $\frac{d Z}{d N}=\frac{\eta}{\eta-1} \cdot W\left[1-\frac{\psi(N) \cdot \psi^{\prime \prime}(N)}{\left[\psi^{\prime}(N)\right]^{2}}\right]$ e a curvatura dada por $\frac{d^{2} Z}{d N^{2}}=\frac{\eta}{\eta-1} \cdot W\left[\frac{2 \psi(N) \psi^{\prime \prime}(N) \psi^{\prime \prime}(N)}{\psi^{\prime}(N) \psi^{\prime}(N) \psi^{\prime}(N)}-\left(\frac{\psi^{\prime}(N) \psi^{\prime \prime}(N)+\psi(N) \psi^{\prime \prime \prime}(N)}{\psi^{\prime}(N) \psi^{\prime}(N)}\right)\right]$,

Ferreira e Michel (1991, nota 2, p. 160) observam que a função será crescente [dZ/ $\mathrm{d} N>0$ ] se $\psi$ ' $(N) \leq 0$; a curvatura da função (o sinal de $\mathrm{d}^{2} Z / \mathrm{d}^{2}$ ) depende da hipótese que se faça sobre a terceira derivada da função de produção [ $\psi$ "' $(N)]$. Ou seja, pode-se considerar que a função tem inclinação positiva, mas com curvatura indeterminada. Do ponto de vista puramente matemático, para que $Z=\phi(N)$ seja positivamente inclinada (isto é, $\mathrm{d} Z / \mathrm{d} N>0$ ), a função de produção $\mathrm{O}=\psi(N)$ pode ter uma primeira derivada $\psi^{\prime}(N)$ positiva ou negativa, o que significa que o produto marginal pode ser crescente ou decrescente. Se a primeira derivada for positiva, o produto marginal do trabalho é crescente (a taxas constantes, crescentes ou decres- 
centes); se for negativa, o produto marginal é decrescente (a taxas constantes, crescentes ou decrescentes). Chick (1983, p. 66) considera que o produto marginal do trabalho é crescente a taxas decrescentes - ou seja, que $\psi^{\prime}(N)>0 \operatorname{com} \psi^{\prime \prime}(N)<0-$ e atribui (sem explicar) um valor maior ou igual a zero para a terceira derivada; ela também considera a possibilidade de o produto marginal ser constante (e igual ao produto médio). Ver também Brady (2004c, p. 528).

Por último, vale observar que as equações (1), (2) e (3) são equivalentes às de Harry G. Johnson, uma das primeiras tentativas de formalização algébrica da função $Z$ de Keynes. Ver Robertson e Johnson (1955), especialmente o apêndice matemático.

\section{Apêndice B - Inclinação da Função Emprego $N=F\left(D^{E F}\right)$}

A inclinação da função emprego $\frac{d N}{d D^{E F}{ }_{W}}$ pode ser escrita como $\frac{d N}{d D^{E F}}\left(\frac{p \psi^{\prime}(N)}{W}\right)$, pois a condição de maximização do lucro exige a igualdade $R M g=C M g$ e, portanto, $\frac{W}{p}=\psi^{\prime}(N)$ ou $p \psi^{\prime}(N)=W$.

Como $\psi^{\prime}(N)=\frac{d O}{d N}$, temos $\frac{d N}{d D^{E F}{ }_{W}}=\frac{d N}{d D^{E F}}\left(\frac{p \frac{d O}{d N}}{W}\right)=\frac{d N}{d D^{E F}{ }_{W}}\left(\frac{p}{W} \frac{d O}{d N}\right)=\frac{d O}{d D^{E F}{ }_{W}}\left(\frac{p}{W}\right)$, ou $\frac{d N}{d D^{E F}}=\frac{d O}{d D^{E F}}\left(\frac{p}{W}\right)\left(\frac{O}{O}\right)$

Como $D^{E F}{ }_{W}=\frac{D^{E F}}{W}=\frac{p O}{W}$, a expressão acima pode ser escrita como $\frac{d N}{d D_{W}^{E F}}=\frac{d O}{d D_{W}^{E F}} \frac{D^{E F}{ }_{W}}{O}$, cujo lado direito é a elasticidade-produto.

Isto significa que a inclinação da função emprego igual à unidade equivale à elasticidade-produto igual à unidade e, qualquer variação na demanda efetiva, se traduz em variação equivalente do produto e do emprego. Ver Keynes (1936, p. 283) e Arthmar e Brady (2009, p. 140). 